\title{
Parameters affecting performance and modeling of biofilters treating alkylbenzene-polluted air
}

\author{
M. Veiga, C. Kennes \\ Applied Microbiology and Biotechnology, March 2001, Volume 55, Issue 2, pp 254- \\ 258
}

DOI: $10.1007 / \mathrm{s} 002530000491$

\begin{abstract}
Both short-term and long-term biofiltration experiments were undertaken with a biofilter inoculated with a defined microbial consortium and treating an alkylbenzene mixture. The results obtained with such a biofilter in short-term experiments were very similar to those obtained with a biofilter inoculated with a nondefined mixed culture, in terms of maximum elimination capacities (70-72 $\mathrm{g} \mathrm{m}^{-3} \mathrm{~h}^{-1}$ ) and the corresponding removal efficiencies (>95\%). However, in long-term experiments, a better performance was reached, with a maximum elimination capacity of $120 \mathrm{~g} \mathrm{~m}^{-3} \mathrm{~h}^{-1}$, corresponding to a removal efficiency $>99 \%$ after 2 years of operation. Inoculation proved to be useful for shortening the start-up period. In the long term, it appeared that biomass distribution was not homogenous along the biofilter, which in some cases resulted in a bad fit between simple model equations and experimental data.
\end{abstract}

\section{Introduction}

Over the past decades, bioreactors have progressively been seen as efficient and costeffective alternatives to more conventional waste gas treatment technologies, such as absorption, adsorption or incineration, provided that contaminant concentrations and air flow rates are in an appropriate range (Ottengraf 1986; Van Groenestijn and Hesselink 1993; Kennes and Thalasso 1998). Initially, biofilters containing natural carriers were used almost exclusively for the removal of odors (Carlson and Leiser 1966; Pomeroy 1982). Later, the technology was extended to a wider range of compounds, including several volatile organic compounds (VOCs). New bioreactor designs and new synthetic carrier materials were also developed.

Although biofiltration has now been used for several years, both at laboratory scale and at industrial scale for the removal of VOCs, the sometimes very different results reported in the literature for similar air pollution problems show the need for further investigation, in order to improve and optimize this technology. Long-term performance needs special attention, since this is of major interest for full-scale applications. Several parameters are known to affect biofilter performance, such as the carrier material, the biocatalyst (microorganisms), temperature, $\mathrm{pH}$, moisture content, pressure drop, gas residence time, etc.

Regarding the biocatalyst, it is important that microorganisms able to degrade the target compound are present in the system. Some air pollutants are biodegradable by a quite wide range of microorganisms found in such natural ecosystems as soil, peat, sludges, etc. (Smith 1990; Kennes and Thalasso 1998). However, in the case of anthropogenic or 
highly recalcitrant compounds, finding cultures adapted to such pollutants might be a more complicated task. Some biofiltration experiments reported in the literature mention the use of defined inocula or pure strains, although the effect of such seed cultures on reactor performance is not clear (Zilli et al. 1993; Kirchner et al. 1987; Shinabe et al. 1995; Smet et al. 1996). Water content is another important parameter in biofiltration studies. The addition of an aqueous phase is a prerequisite for the successful operation of biofilters, since microorganisms need a minimum water content for optimal growth and activity. This aqueous phase may be provided either through humidification of the waste gas or through the external addition of a water phase to the biofilter (Kennes and Thalasso 1998). Optimal moisture content depends on the nature of the carrier material, although it is usually 30-80\% (Ottengraf 1986; Shoda 1991).

In the present study, removal of alkylbenzene vapors was studied with a conventional biofilter. Both shortterm and long-term biofilter performances were evaluated. The influence of several parameters were studied, such as the nature of the inoculum and water content. Biofilter performance was modeled with simple classical equations. Biomass distribution was measured and its effect on reactor modeling was evaluated.

\section{Materials and methods}

\section{Biofiltration studies}

The removal of alkylbenzene pollutants from contaminated air was studied in a downflow, laboratory-scale biofilter run at ambient temperature. The biofilter was filled with perlite as inert support, leading to a total working volume of $2.38 \mathrm{l}$. The size of the sieved carrier material ranged over $4-5 \mathrm{~mm}$. The gas residence time was maintained either at $49 \mathrm{~s}$ in short-term biofiltration studies or at $57 \mathrm{~s}$ in long-term experiments. Short-term and long-term experiments were otherwise performed under identical conditions. The artificial waste gas fed to the biofilter was produced by mixing two different air streams, one passing through a water bath and the other passing through a flask containing the contaminants. The contaminant feed concentration was varied by modifying the flow rate of air passing through that flask. A nutrient solution was occasionally fed to the biofilter; and its composition was as described elsewhere (Kennes et al. 1996). Biomass growth and $\mathrm{pH}$ of the system were not regulated. The microbial consortium used for seeding the reactor was composed of three pure cultures, namely Pseudomonas sp., Bacillus sp. and the fungus Trichosporon beigelei (Veiga et al. 1999). Biofilter performance obtained with this defined consortium was compared to the performance of a biofilter inoculated with a non-defined mixed culture described elsewhere (Kennes et al. 1996) and from which the pure cultures were isolated. Dominant strains present in biofilm samples were isolated and identified as described elsewhere (Veiga et al. 1999).

\section{Batch experiments}

Biodegradation assays were performed in duplicate in 500-ml vials, sealed with viton septa and screw caps. Medium composition was as described elsewhere (Kennes et al. 1996). Initial $\mathrm{pH}$ was around $6.0 \pm 0.1$. Culture bottles containing the mineral medium were autoclaved at $120^{\circ} \mathrm{C}$ for $20 \mathrm{~min}$. Vitamins and trace mineral solutions were filtersterilized and added before seeding the bottles. A calculated amount of pure alkylbenzenes was added to the medium. Gas samples were analyzed by gas chromatography at different time intervals, in order to follow substrate biodegradation. The bottles were shaken at $200 \mathrm{rpm}$ and maintained at $30^{\circ} \mathrm{C}$. 


\section{Analytical methods}

Toluene, ethylbenzene and o-xylene concentrations were analyzed by gas chromatography on a HP-6890 gas chromatograph equipped with a flame ionization detector. A 30-m HP-5 capillary column was used for separating the compounds. Temperature was increased from $60{ }^{\circ} \mathrm{C}$ to $90^{\circ} \mathrm{C}$ for the analysis, with a temperature increase of $5{ }^{\circ} \mathrm{C} \mathrm{min}{ }^{-1}$.

Protein concentrations were measured using Lowry’s method (Lowry et al. 1951). Bovine serum albumin was used as a standard. To evaluate the total protein concentration present on the support material, perlite granules were removed from the biofilter and treated. Several methods had been checked; and the most efficient one consisted of treating the perlite samples with ultrasound for about $30 \mathrm{~min}$. The support material, which had become blackened as a result of heavy biomass growth, turned white (original color of perlite) after this treatment.

\section{Results}

Effect of the inoculum on the start-up period

In the case of moderately recalcitrant compounds, such as the alkylbenzene mixture used in the present study, inoculating adapted strains could speed-up and shorten the start-up period as shown in Fig. 1. In the figure, data showing outlet concentrations are represented for the first days of operation of biofilters inoculated either with a nondefined mixed culture or with the defined consortium composed of the three strains used as seed culture. The total contaminant feed concentration was $300 \mathrm{mg} \mathrm{m}^{-3}$. A similar initial amount of biomass was used in each case, according to protein concentrations.

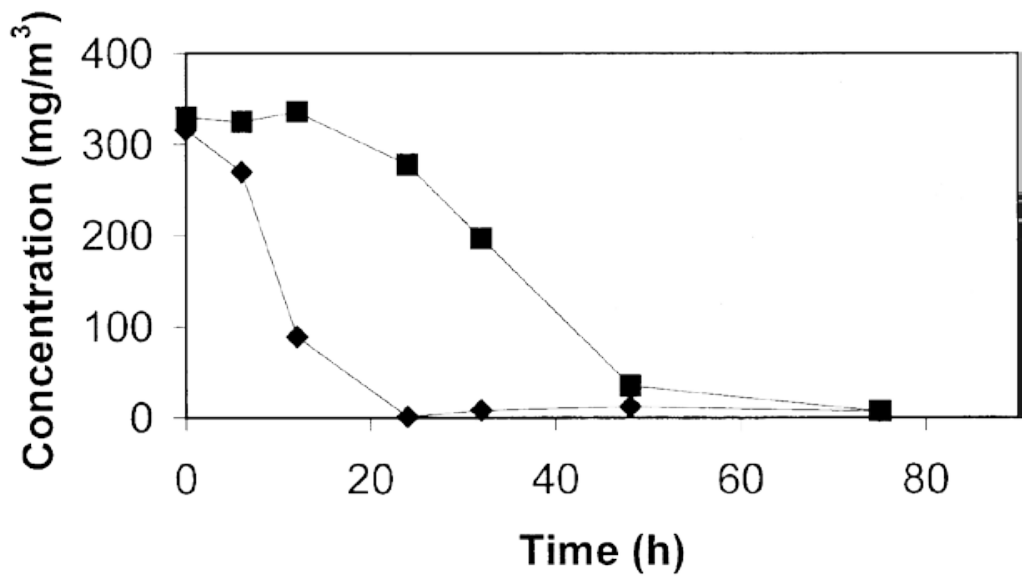

Fig. 1 Outlet concentration versus time after biofilter inoculation, when seeded with a defined consortium composed of three strains $(\diamond)$ or when using a non-defined mixed culture ( $\mathbf{\square})$

\section{Short-term biofilter performance}

Performance of the biofilter treating alkylbenzene vapors was evaluated both for a relatively short period (nearly 3 months) and for a longer period (2 years). During the short-term experiment, performance of the biofilter inoculated with the defined consortium was compared to results obtained previously (Kennes et al. 1996) with a similar biofilter inoculated with a nondefined mixed culture, from which the pure cultures were isolated and used as inoculum in the present study. The total inlet concentration varied between $300 \mathrm{mg} \mathrm{m}^{-3}$ and $1500 \mathrm{mg} \mathrm{m}^{-3}$, using similar concentrations of each of the three compounds. Figure 2 shows the percentage of contaminant removed (in terms of inlet concentration) in both biofilters, using similar 
running conditions. As can be observed, very similar results were obtained in both cases. The medium was purposely not buffered. Maximum elimination capacities of around $70-72 \mathrm{~g} \mathrm{~m}^{-3} \mathrm{~h}^{-1}$ were reached, despite the natural acidification of the medium, with $\mathrm{pH}$ dropping to minimum values close to 4.0 with the defined consortium. Occasionally a pH of 3.5-3.6 was also reached. Such relatively strong acidification was also previously observed with the non-defined mixed culture, down to a minimum $\mathrm{pH}$ of 4.2 (Kennes et al. 1996). After 2 months of operation, carrier samples were removed from the biofilter inoculated with the defined consortium. The samples were serially diluted and grown on plates. According to observations under the microscope, Bacilluslike, Pseudomonas-like and Trichosporon-like strains were still the three dominant microorganisms present, although no further tests were undertaken with these isolates in this short-term experiment. Identification of the dominant strains was later performed during the long-term experiment.

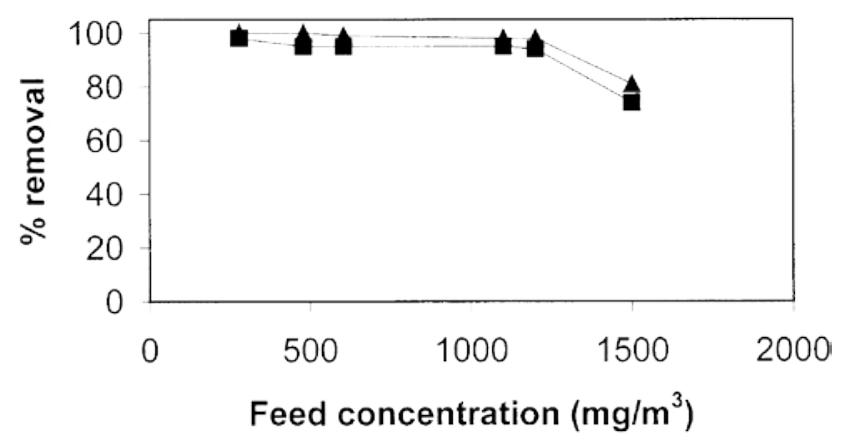

Fig. 2 Removal efficiency versus inlet alkylbenzene (TEX) concentration reached in short-term experiments for biofilters inoculated with a defined consortium composed of three strains ( $\boldsymbol{\Delta}$ ) or using a non-defined mixed culture ( $\mathbf{\square})$

\section{Long-term biofilter performance}

In the long-term experiment, the biofilter was operated for a period of around 2 years, without any control of biomass growth. Inlet concentrations usually ranged over about $100-1,000 \mathrm{mg} \mathrm{m} \mathrm{m}^{-3}$. Pressure drop was basically negligible during the first year of operation. During the second year of operation, pressure drop reached a maximum value of $98 \mathrm{~Pa} \mathrm{~m}^{-1}$ at the end of the study, at a superficial gas velocity of $39 \mathrm{~m} \mathrm{~h}^{-1}$. Such pressure drop is still relatively low, compared to results summarized in the literature for several carrier materials for which more than ten-fold higher pressure drops have been reported in some cases (Kennes and Thalasso 1998).

During this long-term experiment, the maximum elimination capacity (which was only estimated after several months of operation) was higher than during the short-term assay. The maximum elimination capacity for a removal efficiency above $99 \%$, evaluated at the end of the second year of operation, reached $120 \mathrm{~g} \mathrm{~m}^{-3} \mathrm{~h}^{-1}$. The removal of each of the three compounds, for various inlet concentrations, is shown in Fig. 3a. 

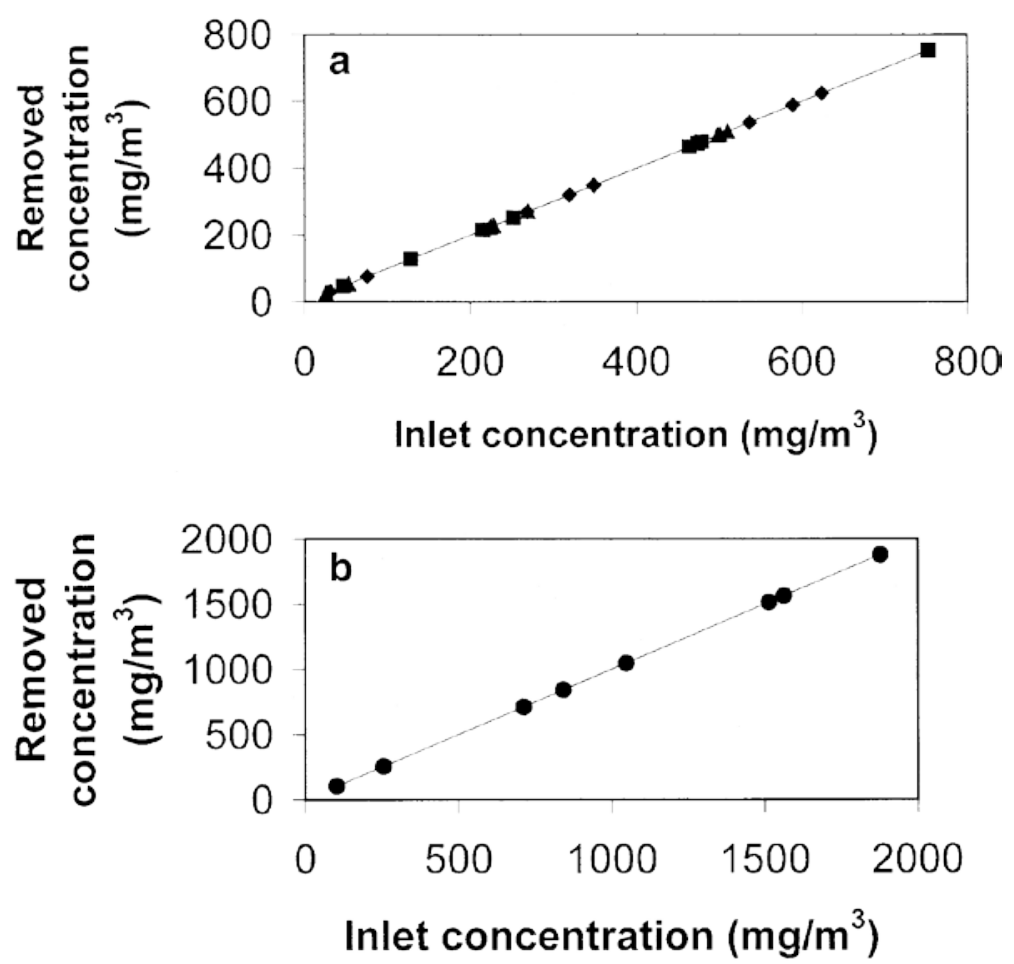

Fig. 3a Removed toluene ( $\boldsymbol{\square})$, ethylbenzene $(\bullet)$ and o-xylene $(\boldsymbol{\Delta})$ versus feed concentrations; b removed total TEX concentration $(\bullet)$

versus inlet TEX concentration

Taking these results into account, it is highly probable that a still higher maximum elimination capacity could have been reached, since a basically complete removal of all three compounds was reached at the highest inlet concentrations tested (Fig. 3b). During the second year, it was observed that the removal efficiency only dropped when the addition of the aqueous phase was suppressed for a relatively long period of time. A high elimination capacity could be maintained for at least 4 weeks when suppressing the addition of the aqueous phase. However, if this was extended for periods longer than 1 month, biofilter efficiency did drop sharply over time. With perlite as carrier, elimination capacity started decreasing significantly when the water content dropped below 35-40\% (Fig. 4). However, the original performance was recovered in less than $24 \mathrm{~h}$, when the regular water supply was restored.

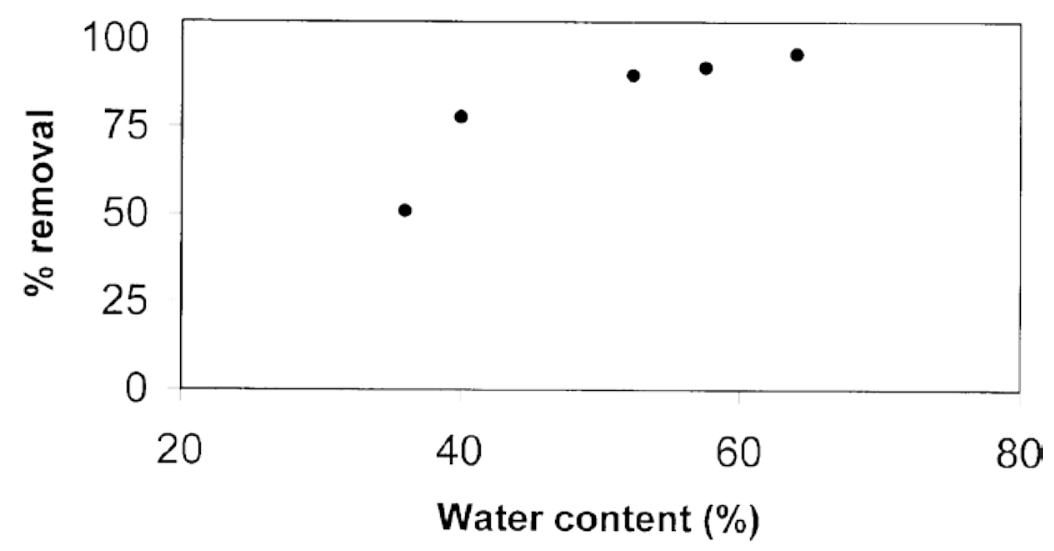

Fig. 4 Effect of water content on removal efficiency at a substrate mass loading rate of $40 \mathrm{~g} \mathrm{~m}-3 \mathrm{~h}-1$ 
In the long-term experiment, the biofilter was operated for a period of around 2 years, without any control of biomass growth. Inlet concentrations usually ranged over about $100-1,000 \mathrm{mg} \mathrm{m}^{-3}$. Pressure drop was basically negligible during the first year of operation. During the second year of operation, pressure drop reached a maximum value of $98 \mathrm{~Pa} \mathrm{~m}^{-1}$ at the end of the study, at a superficial gas velocity of $39 \mathrm{~m} \mathrm{~h}^{-1}$. Such pressure drop is still relatively low, compared to results summarized in the literature for several carrier materials for which more than ten-fold higher pressure drops have been reported in some cases (Kennes and Thalasso 1998).

During this long-term experiment, the maximum elimination capacity (which was only estimated after several months of operation) was higher than during the short-term assay. The maximum elimination capacity for a removal efficiency above 99\%, evaluated at the end of the second year of operation, reached $120 \mathrm{~g} \mathrm{~m}^{-3} \mathrm{~h}^{-1}$. The removal of each of the three compounds, for various inlet concentrations, is shown in Fig. 3a. Taking these results into account, it is highly probable that a still higher maximum elimination capacity could have been reached, since a basically complete removal of all three compounds was reached at the highest inlet concentrations tested (Fig. 3b). During the second year, it was observed that the removal efficiency only dropped when the addition of the aqueous phase was suppressed for a relatively long period of time. A high elimination capacity could be maintained for at least 4 weeks when suppressing the addition of the aqueous phase. However, if this was extended for periods longer than 1 month, biofilter efficiency did drop sharply over time. With perlite as carrier, elimination capacity started decreasing significantly when the water content dropped below 35-40\% (Fig. 4). However, the original performance was recovered in less than $24 \mathrm{~h}$, when the regular water supply was restored.

\section{Modeling biofilter performance}

In a previous study (Veiga et al. 1999), undertaken with the same biofilter, but inoculated with a non-defined mixed culture, it was shown that the biofilter was operating under reaction-limited conditions with zero-order kinetics at the concentrations used in the present study. Under such conditions and provided assumptions detailed elsewhere are correct (Ottengraf 1986), the following equation should be valid for modeling biofilter performance: $D=(K . H) /(C . U)$, where $D$ is the degree of conversion, $\mathrm{K}$ is the zero-order rate constant $\left(\mathrm{g} \mathrm{m}^{-3} \mathrm{~s}^{-1}\right), \mathrm{H}$ is the height of the filter bed (m), C is the inlet alkylbenzene concentration $\left(\mathrm{g} \mathrm{m}^{-3}\right)$ and $\mathrm{U}$ is the superficial gas velocity $\left(\mathrm{m} \mathrm{s}^{-1}\right)$. 

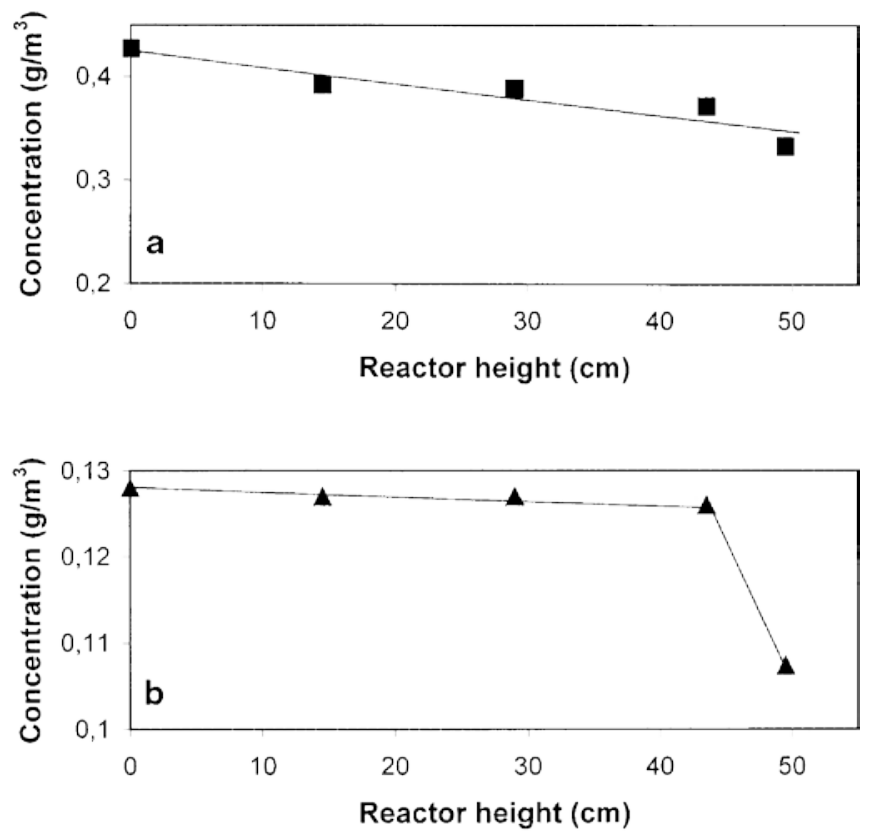

Fig. 5 Removal profiles of (a) toluene ( $\boldsymbol{\square})$ and (b) o-xylene ( $\boldsymbol{\Delta}$ ) along reactor height

A good fit between model equation and experimental data should lead to a straight line when plotting pollutant concentrations versus reactor height. Typical results are represented in Fig. 5. The low inlet concentrations and low removal efficiencies shown in the figure simply result from the fact that these data were generated when the biofilter was operated at a low water content. One can easily observe the good fit between experimental and theoretical data in the case of toluene (Fig. 5a). This was also true for ethylbenzene (data not shown). However, it was not the case for o-xylene (Fig. 5b). This behavior might result from a non-homogenous biomass distribution on the carrier material, as studied in the experiments described below. It is also worth noting that at low water levels, the removal efficiency decreased more significantly in the case of the xylene isomer than for the other two alkylbenzenes. The inlet concentration of o-xylene was therefore also reduced during that period. Quantitative and qualitative characterization of the biomass One of the conditions that should be fulfilled in order to obtain a linear removal profile along the biofilter is a homogenous biomass distribution, both from a quantitative and a qualitative viewpoint. The total protein concentration in the biofilter after 2 years of operation was $6.55 \mathrm{~g}$, although the biomass was not uniformly distributed on the carrier. The protein concentration along the reactor height linearly decreased from a value of $8.84 \mathrm{mg}$ protein $\mathrm{g}^{-1}$ support (i.e. perlite + biomass) near the inlet of the biofilter to $5.25 \mathrm{mg} \mathrm{g}^{-1}$ support near the outlet of the system, meaning a quantitative fluctuation of more than $40 \%$.

Biomass distribution was also evaluated from a qualitative viewpoint. Carrier samples taken from the upper part (inlet) of the biofilter and from the lower part (outlet) were serially diluted and grown on plates. Three plates were used per dilution at the two highest dilutions. Colonies obtained at these highest dilutions were isolated. Although Trichosporon-like yeasts were still found on some plates according to microscopic studies, this organism was basically not present on plates corresponding to the two highest dilutions. Isolates obtained from these plates showed that a Bacillus strain was dominant at the highest dilutions of carrier samples from the lower part of the biofilter, while a Pseudomonas strain was dominant in the higher part of the biofilter. Both microorganisms were able to degrade all three alkylbenzene compounds in batch vials, 
except for the Pseudomonas strain, which was a poor o-xylene degrader. It is also worth mentioning that a similar behavior was originally observed with both bacterial isolates used in the defined mixed seed culture (Veiga et al. 1999). Significant growth of new fungal strains was also evident in the biofilter.

\section{Discussion}

Since bioreactors used for waste treatment in general are being run under non-sterile conditions, it is often not very clear whether inoculating pure cultures makes sense in such systems. It has already been observed that in the long run, selective pressure might indeed lead to a progressive wash-out of the seed culture (Fritsche and Lechner 1992). In the present work, irrespective of the subsequent fate of the strains, the results show the favorable effect on the start-up period of inoculating pure cultures, since pollutant biodegradation started immediately after inoculation and near-complete contaminant removal was reached on the first day of operation.

After the start-up period, full-scale biofilters need to be run under reliable and stable conditions for at least several years, although only a few laboratory-scale studies report reactor performance over periods of more than 1 year. Elimination capacities of $120 \mathrm{~g}$ $\mathrm{m}^{-3} \mathrm{~h}^{-1}$, with removal efficiencies above 99\% and low pressure drops could still be maintained after 2 years of operation, using perlite as carrier material. Such elimination capacity is quite high, compared to other results obtained with identical or similar contaminants (Table 1). The higher elimination capacity reached in this long-term experiment (120 $\mathrm{g} \mathrm{m}^{-3} \mathrm{~h}^{-1}$ ), compared to short-term assays (70-72 $\mathrm{g} \mathrm{m}^{-3} \mathrm{~h}^{-1}$ ) might have resulted from a better adaptation of the microbial community in the long term and growth of new, mainly fungal, strains. During the long-term assay, elimination capacity did occasionally drop with time. In the first stage, it was believed that such decrease resulted from partial clogging, as a result of long-term operation (Veiga et al. 2000). However, pressure drop remained low and it was later confirmed experimentally that the reduced performance resulted from too low a water content.

\begin{tabular}{lcll}
\hline Compound(s) & E.C. max. & R.E. max. & References \\
\hline BTEX & 5.0 & $<40 \%$ (total) & Miller and Canter 1991 \\
BTEX & 50.0 & $>75 \%$ (total) & Togna and Singh 1994 \\
TEX & 70.0 & $>95 \%$ (total) & Kennes et al. 1996 \\
TEX & 120.0 & $99 \%$ (total) & Present study \\
TX & 88.0 & $70 \%(T), 50 \%(X)$ & Jorio et al. 1998 \\
T & 110.0 & Aprox. 90\% & Matteau and Ramsay 1997 \\
T & 60.0 & - & Hwang and Tang 1997 \\
B & 11.5 & $>90 \%$ & Zhou et al. 1998a \\
\hline
\end{tabular}

Table 1 Maximum elimination capacities and corresponding maximum removal efficiencies obtained with biofilters fed benzene (B) and/or alkylbenzenes (toluene T, ethylbenzene E and o-xylene X). E.C. max maximum elimination capacity $\left(\mathrm{g} \mathrm{m}^{-3} \mathrm{~h}^{-1}\right)$, R.E. max maximum removal efficiency.

a Trickling biofilter

Biofilter performance can often be modeled by simple equations (Ottengraf 1986), provided some assumptions are valid, e.g. the presence of a homogenous biomass distribution on the filter bed. Nevertheless, nonhomogenous biomass distribution may often be the rule rather than the exception, leading to a bad fit between model equations and experimental data, as observed in this work (Fig. 5). Indeed, toluene and 
ethylbenzene were usually preferentially biodegraded in the upper part of the biofilter while o-xylene was basically removed near the outlet of the system. Such nonhomogenous biomass distribution had been observed in a biofilter fed styrene, although in such a case fluctuations were slightly less than $20 \%$ after 300 days of operation (Cox et al. 1997), compared with the $40 \%$ fluctuation measured in this work. The same phenomenon was reported in the case of a biofilter filled with porous silicate pellets and used for treating toluene-contaminated air (Song and Kinney 2000), although biomass distribution could in such case be regulated to some extent by alternating downflow and upflow operating conditions.

\section{Acknowledgements}

The present work was financed by projects AMB 98-0288 (CICYT) and PGIDT 99 PGXI 10303A (Xunta de Galicia). We thank S. Mondelo and L. Amor for their collaboration during the experimental studies.

\section{References}

Carlson DA, Leiser CP (1966) Soil beds for the control of sewage odors. J Water Pollut Control Fed 38:829-840

Cox HHJ, Moerman RE, Baalen S van, Heiningen WNM van, Doddema HJ, Harder W (1997) Performance of a styrenedegrading biofilter containing the yeast Exophiala jeanselmei. Biotechnol Bioeng 53:259-266

Fritsche K, Lechner U (1992) Einsatz eines chlorphenolverwertenden Bakterienstammes zur Abluftreinigung Biofilter. In: Dragt AJ, Ham J van (eds) Biotechniques for air pollution abatement and odour control policies. Elsevier, London, pp 287-292

Hwang S-J, Tang H-M (1997) Kinetic behavior of the toluene biofiltration process. J Air Waste Manag Assoc 47:664-673

Jorio H, Kiared K, Brzezinski R, Leroux A, Viel G, Heitz M (1998) Treatment of air polluted with high concentrations of toluene and xylene in a pilot-scale biofilter. $\mathrm{J}$ Chem Technol Biotechnol 73:183-196

Kennes C, Thalasso F (1998) Waste gas biotreatment technology. J Chem Technol Biotechnol 72:303-319

Kennes C, Cox HHJ, Doddema HJ, Harder W (1996) Design and performance of biofilters for the removal of alkylbenzene vapors. J Chem Technol Biotechnol 66:300304

Kirchner K, Hauk G, Rehm HJ (1987) Exhaust gas purification using immobilised monocultures (biocatalysts). Appl Microbiol Biotechnol 26:579-587

Lowry OH, Rosebrough NK, Farr AL, Randall RJ (1951) Protein measurement with the Folin phenol reagent. J Biol Chem 195: 265-275

Matteau Y, Ramsay B (1997) Active compost biofiltration of toluene. Biodegradation 8:135-141

Miller DE, Canter LW (1991) Control of aromatic waste air streams by soil bioreactors. Environ Prog 10:300-306

Ottengraf SPP (1986) Exhaust gas purification. In: Rehm HJ and Reed G (eds) Biotechnology, a comprehensive treatise, vol 8. VCH, Weinheim, pp 425-452

Pomeroy RD (1982) Biological treatment of odorous air. J Water Pollut Control Fed 54:1541-1545 
Shinabe K, Oketani S, Ochi T, Matsumura M (1995) Characteristics of hydrogen sulfide removal by Thiobacillus thiooxidans KS1 isolated from a carrier packed biological deodorization system. J Ferment Bioeng 80:592-598

Shoda M (1991) Methods for the biological treatment of exhaust gases. In: Martin AM (ed) Biological degradation of wastes. Elsevier, London, pp 31-46

Smet E, Chasaya G, Van Langenhoven H, Verstraete W (1996) The effect of inoculation and the type of carrier material used on the biofiltration of methyl sulfides. Appl Microbiol Biotechnol 45:293-298

Smith MR (1990) The biodegradation of aromatic hydrocarbons by bacteria. Biodegradation 1:191-206

Song JH, Kinney KA (2000) Biodegradation capacity and enzymatic activity in a vaporphase biofilm reactor. In: Hartmans

S, Lens P (eds) Proc 4th Int Symp Environmental Biotechnology, Noordwijkerhout, The Netherlands, pp 113-116

Togna P, Singh M (1994) Biological vapor-phase treatment using biofilter and biotrickling filter reactors: practical operating regimes. Environ Prog 13:94-97

Van Groenestijn JW, Hesselink PGM (1993) Biotechniques for air pollution control. Biodegradation 4:283-301

Veiga MC, Fraga M, Amor L, Kennes C (1999) Biofilter performance and characterization of a biocatalyst degrading alkylbenzene gases. Biodegradation 10:169176

Veiga MC, Mondelo S, Amor L, Kennes C (2000) Long-term performance of a biofilter removing alkylbenzene vapors. In: Hartmans S, Lens P (eds) Proc 4th Int Symp Environmental Biotechnology, Noordwijkerhout, The Netherlands, pp 456-459

Zhou Q, Huang YL, Tseng D-H, Shim H, Yang S-T (1998) A trickling fibrous-bed bioreactor for biofiltration of benzene in air. J Chem Technol Biotechnol 73:359-368

Zilli M, Converti A, Lodi A, Del Borghi M, Ferraiolo G (1993) Phenol removal from waste gases with a biological filter by Pseudomonas putida. Biotechnol Bioeng 41:693699 